\title{
A resource-based view on the interactions of university researchers
}

\author{
Frank J. van Rijnsoever*, Laurens K. Hessels, Rens L.J. Vandeberg \\ Department of Innovation Studies, Utrecht University, PO Box 80115, NL-3508TC Utrecht, Netherlands
}

\section{A R T I C L E I N F O}

\section{Article history:}

Received 20 January 2007

Received in revised form 14 April 2008

Accepted 25 April 2008

Available online 4 June 2008

\section{Keywords:}

Research collaboration

Science-industry interaction

Individual researcher

Resource-based view

\begin{abstract}
A B S T R A C T
The high value of collaboration among scientists and of interactions of university researchers with industry is generally acknowledged. In this study we explain the use of different knowledge networks at the individual level from a resource-based perspective. This involves viewing networks as a resource that offers competitive advantages to an individual university researcher in terms of career development. Our results show that networking and career development are strongly related, but it is important to distinguish between different types of networks. Although networks on various levels (faculty, university, scientific, industrial) show strong correlations, we found three significant differences. First, networking within one's own faculty and with researchers from other universities stimulates careers, while interactions with industry do not. Second, during the course of an academic career a researcher's scientific network activity first rises, but then declines after about 20 years. Science-industry collaboration, however, continuously increases. Third, the personality trait 'global innovativeness' positively influences science-science interactions, but not science-industry interactions.
\end{abstract}

(C) 2008 Published by Elsevier B.V.

\section{Introduction}

There is a broad consensus about the importance of active networking in science. Current insights in innovation studies indicate the value of intensive interactions between scientists and extra-academic actors. Innovation scholars recommend policy makers to create incentives that stimulate interactions between scientists and other societal actors, such as industrial companies (Kaufmann and Todtling, 2001; Smits and Den Hertog, 2007; Etzkowitz and Leydesdorff, 2000).

Networking and cooperation are also conceived to contribute to scientific success. Several studies provide evidence that research collaboration enhances scientists' productivity (e.g. Lee and Bozeman, 2005; Landry et al., 1996; Harman, 1999). In addition, it is clear that nowadays

\footnotetext{
* Corresponding author. Fax: +31 302532746.

E-mail address: f.vanrijnsoever@geo.uu.nl (F.J. van Rijnsoever).
}

networks constitute an extremely valuable resource for scientists for acquiring contracts and funding (Nieminen and Kaukonen, 2001; Harman, 2001).

Besides evidence about the positive effects of intensive interactions of scientists, one can find numerous publications claiming that these interactions are currently increasing. Although the various authors use different concepts, such as 'Mode 2' (Gibbons et al., 1994), 'Academic Capitalism' (Slaughter and Leslie, 1997), 'Post-Academic Science' (Ziman, 2000) and 'Triple Helix of government, university and industry' (Etzkowitz and Leydesdorff, 1998), they all include the observation of a trend of increasing collaborations and networking in science.

The literature on this topic, however, shows some significant limitations. First, it is dominated by a macro perspective, addressing the trends on a high aggregation level without taking into account the position of individual scientists (Tuunainen, 2005; Albert, 2003). Second, there is an emphasis on describing, rather than explaining these developments (Shinn, 2002; Weingart, 1997). Third, 
notions like Mode 2 are accused of carrying a normative flavour and suffer from a lack of empirical support (Hessels and van Lente, 2008).

Against this background, the current paper intends to contribute to the understanding of knowledge networks from a micro perspective by investigating the factors that influence the intensity of the interactions that university researchers have with academic colleagues and with firms. There is a vast volume of literature that describes either the collaboration among scientists (for example Melin and Persson, 1996; Feist, 1998; Melin, 2000; Oh et al., 2005) or the collaboration between science and industry (MeyerKrahmer and Schmoch, 1998; Kaufmann and Todtling, 2001; Meeus and Oerlemans, 2004; Laursen and Salter, 2004; Fontana et al., 2006).

Our first contribution to these two strands of literature is that we compare science-science collaboration with science-industry collaboration. We show that science-science collaboration is related to the development of an academic career, while science-industry collaboration is not.

Our second contribution is of a theoretical nature. We apply a resource-based view (Penrose, 1959; Barney, 1991) as an explanatory mechanism for our findings. Whereas the resource-based view is normally used at the level of organizations (firms), for the current study we extend its application to the level of individuals, and more in particular, scientific researchers.

Our final contribution relates to the type of data used. This study uses data from a survey among researchers of Utrecht University, a broad research university in the middle of The Netherlands. This is a more direct type of data collection next to the large amount of bibliometric studies on the topic of scientific collaboration (e.g. Oh et al., 2005). However, the validity of bibliometric studies rests on the crucial assumption that co-authors are identical to co-operators. Empirical research has shown that this is not always the case (Laudel, 2002; Katz and Martin, 1997).

We will limit our focus to science-science interactions and science-industry interactions. Although contacts with government departments, public research institutes and NGOs may also be (increasingly) important for the production of knowledge (Gibbons et al., 1994), they fall outside the scope of this study.

A gained understanding of the factors that determine network activity of individual scientists has both theoretical and practical relevance. Theoretically, it contributes to the understanding of the relationships that scientists have with each other and with external actors. By addressing the factors that influence these interactions, we provide insight in the position of individual scientists as strategic actors attempting to effectively use the resources available to them. Its practical value is that it indicates points of departure for policy makers aiming to stimulate scientists' network activity.

\section{A resource-based view on research collaboration}

The starting point of the this paper is that the increased interaction between science and industry can be explained from a resource-based view (Penrose, 1959; Barney, 1991) and to some extent from a knowledge based perspective (Cohen and Levinthal, 1990; Kogut and Zander, 1992; Grant, 1996), which is a refinement of the resource-based view (Meeus and Oerlemans, 2004).

These theories are normally applied at an organizational level, but in this paper we use them at an individual level.

A university is a professional organization (Mintzberg, 1989), for which success depends to a large extent on the work of its individual researchers. In general, organizations can be regarded as coalitions whose members and stakeholders seek to maximize their personal goals (Cyert and March, 1963). Therefore it makes sense to view these collaborations at the individual level.

The basic argument of the resource-based view is that firms integrate knowledge and other resources to create organizational capabilities to gain a competitive advantage (Barney, 1991; Grant, 1996). Firms' activities are shaped by a strategic balance between exploration and exploitation of knowledge (March, 1991). This explored knowledge can originate inside the organization or it may be acquired externally, for example through cooperation (Nelson and Winter, 1982; Oerlemans and Meeus, 1998). The applicability of these type of knowledge based theories on the individual level has been shown by Aversi et al. (1999), Devetag (1999) and Van Rijnsoever and Castaldi (2008), but these were not on the resource-based view. We show which of the resources a scientist has, are related to networking and academic rank.

We expect the resource-based approach to be a powerful explanatory mechanism for networking among researchers, because through network activity scientists can acquire and assimilate new knowledge.

The resource-based explanation for collaboration shows a lot of similarity with explanations that originate from the sociology of science. According to Latour and Woolgar (1979) scientist work for (peer) recognition which in the long run leads to new funding for research and again recognition: the credibility cycle. Forerunners of this cycle are Bourdieu (1974) describing competition between scientists as competitive investments in symbolic capital, and Hagstrom (1966) who refers to gift-exchanging: scientists give away information for free and in return receive gifts in the form of recognition, prizes or funding. From this perspective scientists can be seen to be working for a competitive advantage. The competitive advantage of an individual researcher has several dimensions: successful cooperation can lead to a larger number of publications, advancement in academic rank, and it strengthens one's position in the competition for research grants.

Sociologists of science explain the differences in success between scientists by the Matthew effect (Merton, 1968). They state that a certain amount of built up symbolic capital leads to the accelerated accumulation of additional capital compared to scientists lacking this threshold amount of capital. The networks involved in the exchange of knowledge and gifts are described as invisible colleges (Crane, 1970) and as communities of practice (Wenger, 1998). People interested in similar topics exchange knowledge in networks, because this is a way of sharing existing tacit knowledge, nurturing new knowledge, developing social capital and stimulating innovation. The aggregation of 


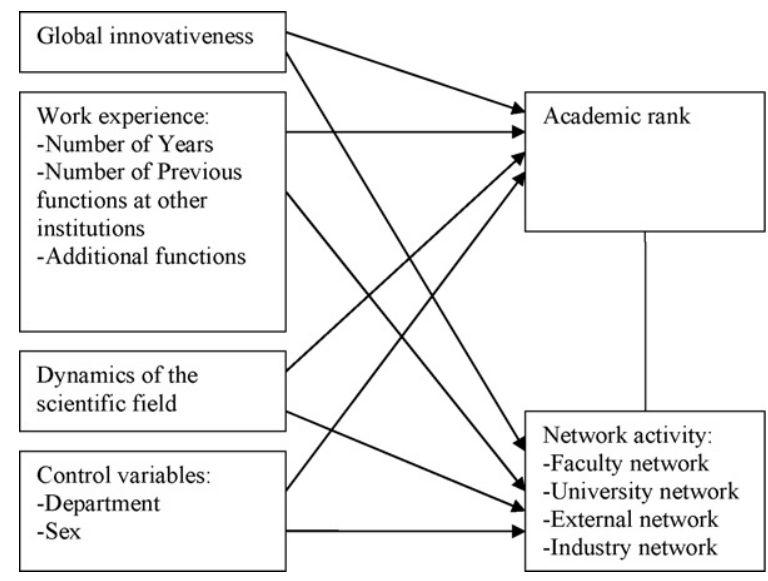

Fig. 1. Our theoretical research model for scientific collaboration.

resources within a durable institutionalised network based on mutual acquaintance and recognition can be called social capital (Bourdieu, 1983). Networking can thus give access to valuable resources for a scientist.

Recently many studies have been conducted in search of the reasons for collaboration (e.g. Melin, 2000; Katz and Martin, 1997; Beaver and Rosen, 1978; see Bozeman and Corley, 2004 for an extensive overview). Reasons reported for collaborating in these studies were: access to expertise, cross fertilisation across disciplines, improving access to funds, obtaining prestige or visibility, learning tacit knowledge about a technique, pooling knowledge for tackling large and complex problems, enhancing productivity, educating a student, increasing specialization of science and for fun and pleasure. These studies show that the reasons for collaboration very often relate to the individual's own resource stock which can be used to gain a competitive advantage. This makes the use of the resource-based view a suitable tool to employ here.

Our research model is displayed in Fig. 1. On the left side the independent variables researched with causal relationships are displayed, on the right side the dependent variables are displayed. We have chosen to model both network activity and academic rank as dependent variables, because these are so related that it not possible to discern a causal relationship between them. Both co-evolve over time. The model is explained in details below; we discuss the concepts and the expected relationships between the variables.

\section{Dependent variables}

\subsection{Network activity}

To enable quantitative analysis of 'networking', we introduce the concept of 'network activity'. Network activity is the degree to which the researchers use their contacts for research purposes. These contacts can be of different types, ranging from formal collaborations to informal contacts. We are aware that scientific work is also carried out in close-knitted groups that defy formal organizational boundaries. For conceptual clarity, however, we have cho- sen the individual researcher as our unit of analysis; we regard working in a group as participating in a network with faculty members (i.e. direct colleagues). The parameter that is of our interest here is the affiliation of the persons that are part of the network. This study distinguishes four types of affiliations at which a scientist can have contacts.

- The faculty network, including only contacts within a researcher's faculty.

- The university network, including all contacts within a researcher's university, but outside his/her faculty.

- The external network, including all contacts with researchers working at other universities.

- The industrial network, including all contacts with people working in private companies.

It is important to distinguish between these levels, because the nature of the relationships can vary greatly. Within a faculty, for example, there are probably more mentor-mentee relationships, while at a university level there may be more interdisciplinary collaborations. The external network will probably contain more contacts resulting from the past occupations. Possible relationships with industry are diverse (Carayol, 2003); a researcher can be a customer for materials, the company can be an object of a case study, a researcher can be a supplier of knowledge, the relation can involve collaborative research, the company can fund the chair of the researcher or the company can be a spin-off of the university

\subsection{Academic rank}

Our second dependent variable is a researchers academic rank in terms of the path to a full professorship. Network activity and academic rank co-evolve over time, there is no clear causality. Higher academic rank probably leads to more network activity, but network activity is also an important resource in the advancement of an academic career. In general the rule applies that the more senior a researcher is, the more years of working experience he has had and the more likely it becomes that he has built a network on all levels (Lee and Bozeman, 2005).

In addition, the seniority of a researcher increases network activity at a faculty level, because of an increase in mentoring collaborations (Chin et al., 1998; Lee and Bozeman, 2005; Bozeman and Corley, 2004) and an increase in managerial responsibilities; the latter can also increase university network activity.

In the opposite direction, the social capital concept explains differences in success based on individuals' connections to other people. From this it follows that the larger an individual's network is, the more successful he will be (in relation to other equally oriented individuals). A larger network increases a researcher's productivity in terms of scientific output (Liberman and Wolf, 1998), which is one of the prime determinants for career advance (Lee and Bozeman, 2005; Baruch and Hall, 2004). A strong mentor in a faculty can also be beneficial for a scientific career (Luckhaupt et al., 2005; Chin et al., 1998) and a good network can help a scientist to get access to a scientific 
promotion more easily. This makes a well-kept network a valuable resource for a scientist.

\section{Independent variables}

\subsection{Global innovativeness}

Since our study focuses on individual researchers, it is appropriate to take into account personality traits. Personality can have a significant influence on a series of behaviours displayed by an individual (Ajzen, 2005). Prior research has shown that personality characteristics influence job performance (McCloy et al., 1994) and career advancement (Creed et al., 2004; Baruch and Hall, 2004; Kuncel et al., 2004; Chin et al., 1998). Therefore we aim to identify a personality trait that can predict a scientist's tendency to network.

Over the years, researchers consistently found that an individual's personality can be explained by five factors (McCrae and John, 1992; Feist, 1998; John and Srivastava, 1999; Ajzen, 2005), the so-called 'Big Five': extraversion, agreeableness, conscientiousness, emotional stability versus neuroticism and originality. However, since not all factors are of likely influence on our dependent variables (i.e. present function and network activity); we will confine ourselves here to a more specific measure: global innovativeness. This concept can be defined as the degree to which an individual is receptive to new ideas and makes innovation decisions independently of the communicated experience of others (Midgley and Dowling, 1978). We have chosen for global innovativeness, because knowledge production is all about having new ideas and exploring the unknown, it can thus be a valuable resource for an academic. One way of exploring the unknown is through collaboration. It has been shown that the personality trait global innovativeness is for a large part a combination of these two dimensions (Kwang and Rodrigues, 2002).

Global innovativeness is a continuum between adaption and innovation (Kirton, 1976; Kirton, 2003). In problem solving, people either try to improve on existing solutions (adaption) or they try to find new solutions (innovation). Adaptive individuals, on the one hand, are known to be precise, reliable, think within existing frameworks and prefer to work with well-established procedures. They are more methodological and thorough. Innovators, on the other hand, are less focussed on details and less reliable, but they come up with new perspectives and are more likely to challenge rules and authority (Kirton, 1976). Because of their new perspectives, innovators need other people more to help them implement their broader spectrum of ideas. Adaptive individuals, however, perform best in a constant group on which they can depend; this reduces the need for a larger network. Since innovative individuals seek solutions outside existing structures (Kirton, 1994), they are more able to step outside existing organizational boundaries. With regard to a researcher's own faculty and university, we expect that the more boundaries are crossed, the stronger the effect of global innovativeness on network activity will be.

Concerning the relation with a researcher's present function, we expect that the advancement of an academic career partly depends on having original innovative ideas. On the other hand the advancement in an career also depends on following the correct set of (methodological) rules (Chin et al., 1998; Baruch and Hall, 2004), which is something innovative persons are less capable of (Kirton, 1994). This could prevent the effect from global innovativeness on present function from occurring.

\subsection{Work experience}

We distinguish three dimensions for previous work experience: the length of a scientist's career and whether a scientist has worked previously only at universities and hospitals or also in industry. We also include hospitals specifically, because of the integration of medical faculties within academic hospitals.

The longer a scientist has been active, the more opportunities he has had to build his networks and career (Lee and Bozeman, 2005), so we expect a positive influence on all dependent variables. However, after a number of years the researcher may become more independent. The knowledge supplied by the network becomes incorporated into the researchers' individual knowledge base, which decreases the necessity to continue using the network. This could cause an inverted U-shape in the relationship between years of working experience and network activity. This inverted U-shape is most likely to occur on a faculty level, because the knowledge available there is the most limited and closest to the researchers' knowledge base (compared to the other levels of network activity), and therefore it may become obsolete first.

If a researcher has worked or still works at more universities, we expect his external network to be larger. If a researcher has worked previously in industry or is still working there, we expect that his industry network activity will be larger. In both cases one can assume that there are contacts from earlier days (Melin, 2000). Because having additional functions leads to more network activity, we also expect a positive relationship between additional functions at other universities and academic rank. We expect a negative effect however from past experience in industry on academic rank. A scientist's publication rate negatively depends on the years of work he has done in industry (Dietz and Bozeman, 2005) and this is the prime indicator for career advancement.

\subsection{Dynamics of the scientific field}

By the dynamics of the scientific field we mean the extent to which an individual researcher experiences his own scientific working field to change. Environmental change enhances the need of an individual to find new behaviour patterns or resources that enable the actor to adapt to new environmental demands (Richerson and Boyd, 2005; Bessant et al., 2001). In the case of a scientific researcher these might entail material or knowledge (Melin, 2000). Previous research has shown that in nondynamic environments a specialist approach in terms of resources is optimal, while in a dynamic environment a generalist's approach (e.g. having a broader set of resources) is optimal (Hannan and Freeman, 1989; Cohen 
and Levinthal, 1990), because this enables handling a larger variety of situations. This means that researchers in a dynamic scientific field need to have a broader set of skills, which would encourage them to seek contact with more than one type of institution. Therefore we expect them to collaborate more and have a higher network activity.

\subsection{Control variables}

We add two control variables to the model that are expected to influence network activity and academic rank; the department the researcher is working at and the sex of the researcher. Different scientific fields and organizational units may experience completely different circumstances and may vary therefore in their network activity. In a study after co-authorships Melin and Persson (1996) observed differences in the types of institutions with which collaboration took place. The number of collaborations within the field of medicine, for example, is higher than in mathematics (Liberman and Wolf, 1998; Melin and Persson, 1996). Departments that are more oriented towards applied research can be expected to have more external contacts than departments with a more fundamental perspective. Their work requires being well-informed about their application context and it lends itself more easily to contract research and consultancy. Therefore we add the department in which researchers work as a control variable to our model.

Sex will be added to the model, because it is a standard control variable in behavioural models.

\section{Methods}

\subsection{Sample and data collection}

A survey was administered among the scientific employees ${ }^{1}$ working at Utrecht University. This is a large and broad research university in the centre of The Netherlands, in which all the major scientific disciplines are incorporated. The survey was administered at the faculty of science, the faculty of geosciences and the academic biomedical cluster. To ensure a high response, during a period of two weeks all scientific employees of these faculties were approached personally and asked to fill in the questionnaire. The response was 304 usable questionnaires; the response rate was approximately $17 \%$; the age of the respondents varied between 23 and 74 years, with a mean of 36 . There were 209 male respondents and 94 females.

\subsection{Measurement and analysis}

The questionnaire enquired about the researchers' network activity, past occupations, their current status of employment, the nature of their research, and their global innovativeness.

\footnotetext{
${ }^{1}$ In The Netherlands, PhD students are also fully paid employees of the university.
}

Network activity can be assessed from the perception of the respondent, or by measuring their co-authorships. In the past, bibliometric methods have proven to be practical tools for the study of research cooperation (e.g. Oh et al., 2005), but their validity is contested (Laudel, 2002; LaFollette, 1992; Katz and Martin, 1997). Therefore we have chosen to measure network activity from the perception of the respondent. This can be done by measuring only the actual number of self-reported contacts a respondent uses for research, but respondents opinions might differ about whether and when contact is actually used in research. Bozeman and Corley (2004) prefer this method over the measuring of co-authorships for the reasons mentioned above, but acknowledge the lack of precision in self-reported contacts. That is why we have chosen to crossvalidate this measure with other indicators for network activity. As noted in the theory section, we make a distinction between contacts at a faculty level, university level, other universities and contacts with industry. For each level we asked questions with regard to the number of persons with whom the researcher communicated at least once a month for research purposes. Further we asked how many articles the researcher had published during the last two years in collaboration with others. Finally we measured the activity on scientific mailing lists. These measures were standardized and added together to form a measure for network activity. We also make a distinction between the different types of organization where a researcher has previously worked for or is still working for.

Global innovativeness has been measured with a translated, adapted version of the innovativeness scale by Kirton (1976). The scale consists of 32 five-point items, with scores ranging theoretically between 32 points (extremely adaptive) and 160 points (extremely innovative).

The other variables have been measured with the use of single items, because they are relatively straightforward. The descriptive statistics of the variables are given in Table 1.

A linear mixed model was fitted with a random intercept to account for interdependencies within the departments using the R-program (R Development Core Team, 2006)

Table 1

Descriptive statistics of the variables, valid $N=301$

\begin{tabular}{llr}
\hline & Mean & S.D. \\
\hline Dependent variables & & \\
$\quad$ Faculty network activity & 2.28 & 0.21 \\
University network activity & 2.26 & 0.28 \\
External network activity & 2.23 & 0.35 \\
Industry network activity & 2.25 & 0.31 \\
Academic rank & 2.93 & 1.47 \\
& & \\
Independent variables & & 11.16 \\
Global innovativeness & 98.51 & 10.91 \\
Years of working experience & 10.11 & 1.06 \\
Dynamics scientific field & 3.77 & 1.44 \\
Previous universities & 1.38 & 0.43 \\
Previous hospitals & 0.13 & 1.17 \\
Previous industry & 0.57 & 0.37 \\
Additional functions (Utrecht) & 0.10 & 0.21 \\
External additional functions & 0.03 & 0.38 \\
Additional functions industry & 0.07 & \\
Sex & 209 male, 94 female & \\
\hline
\end{tabular}


and the lme4 package (Bates and Sarkar, 2006). To control for the mediating effects, each analysis was performed in two blocks. The first block only contained the independent variables that are causally related. The second block contained the other (non-causal) variables from our research model; these are the remaining dependent variables from Section 3. Five models were tested, one for academic rank and one for each level of network activity. The performance of each block in the model was measured by the $-2 \log$ likelihood, for each non-causal block we checked whether the addition of the variables improves the model significantly. Additional functions were not used as dependent variables. To test for the inverted U-shape effect of previous years of working experience the variable was squared and added to the models predicting the network activity variables.

To account for possible skewness in the distribution of rank $^{2}$ we also performed an ordinal regression analysis (McCullagh, 1980; McCullagh and Nelder, 1998), which is able to cope with skewness in the distribution. We found no differences in the results of the analyses. For reasons of clarity we will only present the results of the linear mixed model.

\section{Results}

In Table 2 the results of the linear mixed model procedure are displayed. In this section we present and discuss the results of the separate models, and then we compare the results of the models with each other. If required we have performed some additional analyses to confirm our explanation of a result; the results of these analyses are given in the text.

\subsection{Academic rank}

In the first block, the present academic rank is significantly influenced by global innovativeness, the years of working experience and the number of universities the researcher has previously worked at. In this respect there are no differences between the departments. The addition of the variables in the second block improves the model significantly. In the second block global innovativeness and the years of working experience remain influential, but the positive influence of previous universities is replaced by a negative impact of having worked previously in industry. Additional functions at other universities also have a positive relationship with academic rank, as do faculty network activity and external network activity.

These results of global innovativeness indicate that having new and innovative ideas is important for the advancement in a scientific career. The relationship between years of working experience and academic rank is straightforward. The effect of having worked previously at other universities is mediated by non-causal variables, probably by the number of additional functions at other universities

\footnotetext{
2 In our dataset there appears to be an overrepresentation of PhDstudents. Theoretically this is not a problem because in The Netherlands PhD-students are also fully paid employees of universities.
}

and external network activity. According to these results, either the number of contacts a researcher has with other universities is a reason for an institution to employ him, or an externally well-networked researcher has better access to jobs. Having worked in industry in the past has a negative relationship with academic rank. This gives support to the hypothesis of Dietz and Bozeman (2005), who state that scientists who follow a traditional uninterrupted career path are likely to have a higher scientific productivity, and are therefore more likely to achieve a higher academic rank earlier in their career. Working in industry creates a time-lag in academic career development, compared to the researchers that did not work in industry. The relationship between faculty network activity and present function follows the predictions from our theoretical framework. University network activity and industrial network activity have no influence on academic rank.

\subsection{Faculty network activity}

At the faculty level there are significant differences between the rates of network activity of the different departments in the causal block. Global innovativeness is significant at the $10 \%$ level; there is an inverted U-shaped relation between the years of working experience with a turning point at 20 years; the dynamics of the scientific field are significant at the $1 \%$ level. The addition of the variables in the second, non-causal block improves the model significantly. In the second block of the analysis, the relationship between global innovativeness is mediated by the other variables, notably the present function as we predicted. Also the inverted U-shaped has disappeared. Previous work at hospitals is positively significant at the $10 \%$ level. The positive relationship between faculty network activity and present academic rank is also present in this model. Additional functions at other universities have a negative impact at the $10 \%$ level. Network activities at the university level and at other universities also have a positive relationship with network activity at the faculty level.

\subsection{University network activity}

At the university level there are also significant differences between the departments. The effect of global innovativeness is stronger and more significant than at the faculty level. Again there is an inverted U-shaped relationship between years of working experience with the turning point is at 19 years. Having worked previously at universities is positively related at the $10 \%$ level to university network activity. Again, the addition of the variables in the second block improves the model significantly. In the noncausal block the relationships with global innovativeness, the years of working experience and previous universities are again mediated by the other variables. Not surprisingly, having additional functions at Utrecht University is positively related to the network activity at that level. Just as with the faculty network, all levels of network activity within the scientific community are positively related to each other. 
Table 2

Results of the linear mixed model procedures for our five dependent variables

\begin{tabular}{|c|c|c|c|c|c|}
\hline & Academic rank & $\begin{array}{l}\text { Faculty network } \\
\text { activity }\end{array}$ & $\begin{array}{l}\text { University network } \\
\text { activity }\end{array}$ & $\begin{array}{l}\text { External network } \\
\text { activity }\end{array}$ & $\begin{array}{l}\text { Industry network } \\
\text { activity }\end{array}$ \\
\hline Intercept & -0.187 & $1.808^{* * *}$ & $1.648^{* * *}$ & $1.306^{* * *}$ & $1.918^{* *}$ \\
\hline Global innovativeness & $0.024^{* * *}$ & $0.002^{*}$ & $0.003^{* *}$ & $0.007^{* * *}$ & 0.000 \\
\hline Years of working experience & $0.070^{* * *}$ & $0.017^{* * *}$ & $0.015^{* * *}$ & $0.016^{* *}$ & 0.004 \\
\hline Years of working experience ${ }^{2}$ & & $0.000^{* * *}$ & $0.000^{* * *}$ & $0.000^{* *}$ & 0.000 \\
\hline Dynamics scientific field & 0.024 & $0.029^{* * *}$ & $0.027^{*}$ & $0.048^{* * *}$ & $0.052^{* *}$ \\
\hline Previous universities & $0.121^{* *}$ & 0.003 & 0.011 & $0.052^{* * *}$ & $0.031^{* *}$ \\
\hline Previous hospitals & -0.124 & 0.041 & 0.038 & -0.011 & -0.027 \\
\hline Previous firms & -0.083 & 0.002 & -0.011 & 0.002 & $0.039 * *$ \\
\hline Department & & ** & $* * *$ & * & ** \\
\hline Sex & -0.213 & -0.030 & -0.048 & $-0.099^{* *}$ & -0.017 \\
\hline Valid $N$ & 301 & 301 & 301 & 301 & 301 \\
\hline Degrees of freedom & 21 & 22 & 22 & 22 & 22 \\
\hline-2 Log likelihood & 957.950 & -31.722 & 113.464 & 241.757 & 213.309 \\
\hline Intercept & $-4.355^{* * *}$ & $1.082^{* * *}$ & $0.448^{* * *}$ & 0.144 & $1.321^{* * *}$ \\
\hline Global innovativeness & $0.016^{* * *}$ & 0.000 & 0.001 & $0.004^{* * *}$ & -0.002 \\
\hline Years of working experience & $0.064^{* * *}$ & 0.005 & 0.002 & -0.001 & -0.007 \\
\hline Years of working experience ${ }^{2}$ & & $0.000^{*}$ & 0.000 & 0.000 & 0.000 \\
\hline Dynamics scientific field & -0.058 & 0.015 & -0.002 & 0.021 & $0.039^{* *}$ \\
\hline Previous universities & 0.063 & -0.010 & 0.002 & $0.044^{* * *}$ & 0.021 \\
\hline Previous hospitals & -0.186 & $0.042 *$ & 0.006 & -0.030 & -0.026 \\
\hline Previous firms & $-0.105^{*}$ & 0.006 & -0.014 & 0.002 & $0.039^{* * *}$ \\
\hline Department & & ** & $* * *$ & $* * *$ & $* *$ \\
\hline Sex & -0.029 & 0.001 & -0.015 & $-0.071^{*}$ & 0.023 \\
\hline Academic Rank & & $-0.024^{* * *}$ & 0.091 & $0.018^{* *}$ & 0.031 \\
\hline Additional functions (Utrecht) & 0.238 & -0.092 & $0.070^{* *}$ & 0.136 & 0.094 \\
\hline Additional functions universities & $0.888^{* * *}$ & $0.040^{*}$ & -0.051 & -0.050 & 0.099 \\
\hline Additional functions firms & 0.249 & 0.033 & 0.000 & 0.035 & $0.022^{* *}$ \\
\hline Faculty network activity & $1.602^{* * *}$ & & $0.532^{* * *}$ & $0.290^{* * *}$ & 0.169 \\
\hline University network activity & 0.066 & $0.310^{* * *}$ & & $0.263^{* * *}$ & 0.076 \\
\hline External network activity & $0.493^{* *}$ & $0.094^{* * *}$ & $0.146^{* * *}$ & & $0.138^{* *}$ \\
\hline Industry network activity & 0.201 & 0.054 & 0.042 & $0.136^{* *}$ & \\
\hline Valid $N$ & 301 & 301 & 301 & 301 & 301 \\
\hline Degrees of freedom & 28 & 29 & 29 & 29 & 29 \\
\hline-2 Log likelihood & 896.565 & -105.093 & 41.644 & 201.197 & 204.505 \\
\hline$\chi^{2}$ & $61.385^{* * *}$ & $73.371^{* * *}$ & $71.82^{* * *}$ & $40.56^{* * *}$ & 8.804 \\
\hline
\end{tabular}

Estimates are given behind the variable names; ${ }^{*} p<0.1 ;{ }^{* *} p<0.05 ;{ }^{* * *} p<0.01$. The $-2 \log$ likelihood indicates the performance of the block in the model (less is better); the $\chi^{2}$ indicates the increase in performance by the addition of the non-causal variables. The first block only contains the causal variables from our research model; in the second block the non-causal variables are added.

\subsection{External network activity}

The network activity in relation to other universities does not show differences among the departments. Female researchers appear to have a slightly lower external network activity than male researchers. At the level of external networks, global innovativeness has a stronger and more significant effect than it had on the previous levels. Again the inverted U-shape from years of working experience is present with a turning point at 20 years of working experience. Also the dynamics of the scientific field increase external network activity. Again, not very surprisingly, the number of previous universities a researcher has worked at increases the amount of external network activity. The second block is a significant improvement, the effects of sex, global innovativeness, and years of working are again mediated, but global innovativeness remains significant. The number of previous functions at other universities remains significant at the $1 \%$ level and the number of previous functions at firms also becomes positively significant at the $5 \%$ level. Academic rank positively influences external network activity. The other levels of network activity within the scientific community are again of positive influence, but also the network activity with industry is significant at the $5 \%$ level.

\subsection{Industry network activity}

The industry network activity is different at the $5 \%$ level over the departments. The more years of working experience, the larger the industry network activity is. Also the dynamics of the scientific field have a positive effect at the $1 \%$ level. Finally, having worked previously at other universities and firms enlarges the industry network activity. The non-causal variables do not give a significant improvement to the model. The departments remain different at the $10 \%$ level and the dynamics of the scientific field at the $5 \%$ level. The years of working are not significant anymore, because it is mediated by the present academic function. Previously working at universities is not significant anymore, but previously working at firms remains significant at the $1 \%$ level. There is a direct influence of present academic rank (linear mixed models: $F=24.833, p<0.01$ ), but in the non-causal model this effect is mediated by the external network activity. Having additional functions at firms also increases industry network activity. There is no relation- 
ship with the other levels of network activity, except with the external level, which is again positive.

\subsection{Global innovativeness and network activity}

As predicted, the positive effect of global innovativeness on network activity within the scientific community becomes larger as the relation becomes more distant. Innovators are more likely to cross-organizational boundaries than adaptors. This personality trait is rewarded in the form of a higher scientific rank which mediates the main effect.

Surprisingly, innovativeness does not have any effect on industry network activity. Adaptors and innovators use this type of contacts equally. This can be explained by the different forms science-industry relations can have (Carayol, 2003).

\subsection{Previous work experience and network activity}

The years of working experience are related to the amount of network activity on all levels (except industry), through an inverted U-shaped relationship, with a turning point at about 20 years. After approximately 20 years of work the amount of network activity declines, possibly because scientists' knowledge base has grown to a level that one is more able to independently conduct research. Furthermore, a mediating effect by the number of universities a researcher has previously worked at has also moved the turning point of the other levels network activities. The turning points are: faculty level: 20.8 years, university level: 20.2 years, external level: 23.8 years. The decrease in external network activity thus starts at a later point in a researcher's career, as was predicted.

The effect of having worked at other universities suggests that changing universities is a principal way to extend one's own network among the scientific community. Building a scientific network is not just a matter of holding the same position; it also requires some form of action.

A closer look at the data reveals that there is a direct linear effect for industry network activity (estimate $(0.0036$, $p<0.05)$ ) that is not visible due to the addition of the squared term. Also previous functions in industry are an important predictor for the network activity with industry; the same principle applies here as in our former argument. In the non-causal model the effect of working experience is almost completely mediated by present function.

\subsection{Dynamics of the scientific field and network activity}

In the causal models the dynamics of the scientific field experienced by the researchers have a positive influence on network activity at all levels, except at the university level. There also is a direct effect at this level (linear mixed models: $F=8.032, p<0.01$ ), but it is mediated by the other variables. The more dynamic the field is experienced, the larger the network activity is. In the non-causal models the effect is also mediated out for the faculty and the external level. The result that the dynamics of the scientific field have a direct effect on all levels suggests that one function of networking is to cope with a changing environment by getting access to a broader set of skills and resources.
This is confirmed by many of the reasons for scientific collaboration found by Melin (2000) and is in line with the generalist/specialist theory by Hannan and Freeman (1989). A broader set of resources enlarges chances of success in a dynamic environment. This effect is not mediated at the industry level, because there are differences between the variables that determine scientific network activity and industry network activity.

\subsection{Interacting networks}

All three levels of scientific network activity have a positive relationship with each other. Having a larger network increases the possibility of future collaborations, because a larger network creates more possibilities for related knowledge accumulation (Cohen and Levinthal, 1990). Industry network activity, however, is influenced positively only by external scientific networks, but not by the faculty level or the university level. Enlarging one's own network with industry does not happen by staying within the confinements of one's own university; an external orientation is required.

\section{Conclusions and discussion}

\subsection{Resources for academic careers}

Our study confirms that academic rank and network activity are strongly related. Networks are a crucial resource for a scientific career, but they also grow 'naturally' with increasing academic rank. Here, we would like to highlight four more specific findings. First, networking within one's own faculty and with external scientific colleagues turns out to have the largest impact on academic careers. On the other hand, interactions with industry show no relationship with academic rank. Second, we have found empirical evidence for the so-called 'Matthew effect'. The networks on various levels are related, which implies that once a certain threshold level of networking has been attained, the interactions accumulate with increasing ease. Third, we have identified three resources that stimulate networking of individual researchers: having experience at multiple universities, working in a dynamic scientific field, and having an innovative personality. We should stress, that the effect of these factors is not the same for each type of network.

Our fourth finding, which deserves a little more discussion, is that during the first 20 years of a career, the years of working experience also increase the number of contacts, which gives a competitive advantage to the researcher. After this period the level of network activity starts to decline, possibly because the researcher has a sufficient knowledge base so he does not need to use his network as intensively as before. There are of course other possible explanations for this finding. First, it could be that not only the knowledge base has grown sufficiently large, but also other resources like facilities or the reputation of a scientist, which can decrease the need for intensive networking. Second, the observed effect may be due to a historical development rather than individual career patterns. It might also be that scientists working over 20 years belong to 
a generation that is generally less involved in networks and interactions than the younger ones. Third, our finding can be explained by the assumption that scientists generally become less occupied with research activities after a certain point in their career because they have more management responsibilities.

The inverted U-shape is not found for the relationship with industry. The fact that scientists in a late phase of their career decreasingly collaborate with academic colleagues, but increasingly interact with industry may be problematic. It can create a growing gap between the industrial knowledge possessed by senior scientists and the younger scientists. In other words, the knowledge collected in industry by the senior scientists might diffuse insufficiently to the rest of the scientific community.

Our undertaking to apply a resource-based perspective to individuals rather than organizations has thus yielded several interesting findings. By applying the resourcebased view, we have chosen for a rational and functional concept of scientific collaboration. We believe that this is justified if we look at the list of the reasons of collaboration mentioned in Section 2. Note that we looked primarily at network activity, experience and global innovativeness as resources, but other resources are also likely to play a role here. It must be noted that our theory explains network activity by looking at demand for knowledge, which is a prominent reason according to Melin (2000). Networking, however, is not a uni-directional process; it also involves the supply of information to others. Our measurement does not make a clear distinction between supply and demand, but following the reasons for collaboration provided by Melin (2000). We recommend making a clearer distinction between the demand and supply of knowledge in future research.

\subsection{Limits to generalizability}

This study has limitations in terms of generalizability. First, the response rate of the survey is rather low. Many researchers were approached to fill in the questionnaire, but the high rate of non-response is probably due to the low priority many respondents gave to filling in the questionnaire. The sample did contain sufficient respondents of all academic ranks for a statistical analysis, but the total sample was not a representation of the population. Also not all departments had equal response rates. We have attempted to statistically control for these deficits, but it is still difficult generalize our findings to academia in general.

Second, we have only considered only Utrecht University in our study. Although Utrecht University is a large and broad research institution, from a methodological perspective it is again difficult to generalize our findings to academia in general or even to the Dutch situation. Despite these difficulties, the results may very well be indicative for processes that are going on at other universities.

\subsection{Policy recommendations}

Based on our empirical results we wish to discuss the implications of our research. In the following we attempt to make recommendations for policies that stimulate more interactive research practices. ${ }^{3}$

The first recommendation that follows from this study concerns the desirability of flexible career paths. Working experience in industry strongly enhances someone's probability of high network activity with that sector; therefore attracting researchers from private companies is beneficial for the overall knowledge base of a research group. However, our results indicate that at present potential job applicants are not rewarded for their experience outside academia in terms of academic rank. Although being strongly related to years of working experience and the number of universities they have worked for, the present position of the respondents turns out to be slightly negatively influenced by working experience in industry. It is worthwhile exploring the possibilities to increase the career perspectives of researchers with a heterogeneous job history.

The next set of recommendations is related to the working experience of the scientists. Persons with approximately 20 years of working experience, on the one hand, tend to be active networkers; young persons and older persons, on the other hand, tend to have much fewer contacts. Consequently, the latter classes deserve particular attention in order to optimize the exploitation of intellectual capital in the university. If one aims at stimulating network activity, these groups might be the first targets.

First, university policy should stimulate and support the network activity of young researchers with limited experience. One can think of specific facilities to support starting academics in their process of developing more contacts across disciplinary and institutional borders. Possible instruments include internships at other institutions (both commercial and non-profit), courses in communication skills, sponsored meeting/networking platforms or funds that specifically focus on facilitating interdisciplinary and cross-institutional workshops or conferences.

Second, we recommend the development of a set of instruments that aim to limit the decrease in the network activity of older scientists. Older scientists themselves may benefit relatively little from collaborating, but their younger colleagues can certainly benefit from their knowledge. Currently, the transfer of knowledge gained during industrial networking to other university researchers may be hampered. We recommend further research into possible measures to ensure that science-science networking remains rewarding.

Finally, a researcher's network activity is influenced by his global innovativeness, which implies that employing innovative individuals gives universities a competitive advantage. However, other empirical research has shown that, for a good performance of a group, adaptors are required next to innovators (Kirton, 1994), which implies that universities cannot selectively hire innovators only. The results show that the current academic selection system does favour innovators over adaptors in academic rank. For universities exploring possibilities to incorporate global

\footnotetext{
${ }^{3}$ Assuming that interactions between scientists and with other actors are desirable, from an innovation system's perspective.
} 
innovativeness in selection procedures of candidates for tenure tracks is recommendable.

\section{Acknowledgements}

This work has been partly supported by a NWO-MCG grant (MCG-C03-03) and by the Dutch Knowledge network on System Innovations (KSI). The authors thank Rogier Donders, Carolina Castaldi, Henk van Peer and the Bache- lor students of Science \& Innovation Management (Utrecht University), who helped to design the research and to collect the data through the distribution of the questionnaires amongst the researchers at Utrecht University. Two anonymous reviewers are acknowledged for their valuable comments.

\section{Appendix A. The correlation table $(N=301)$}

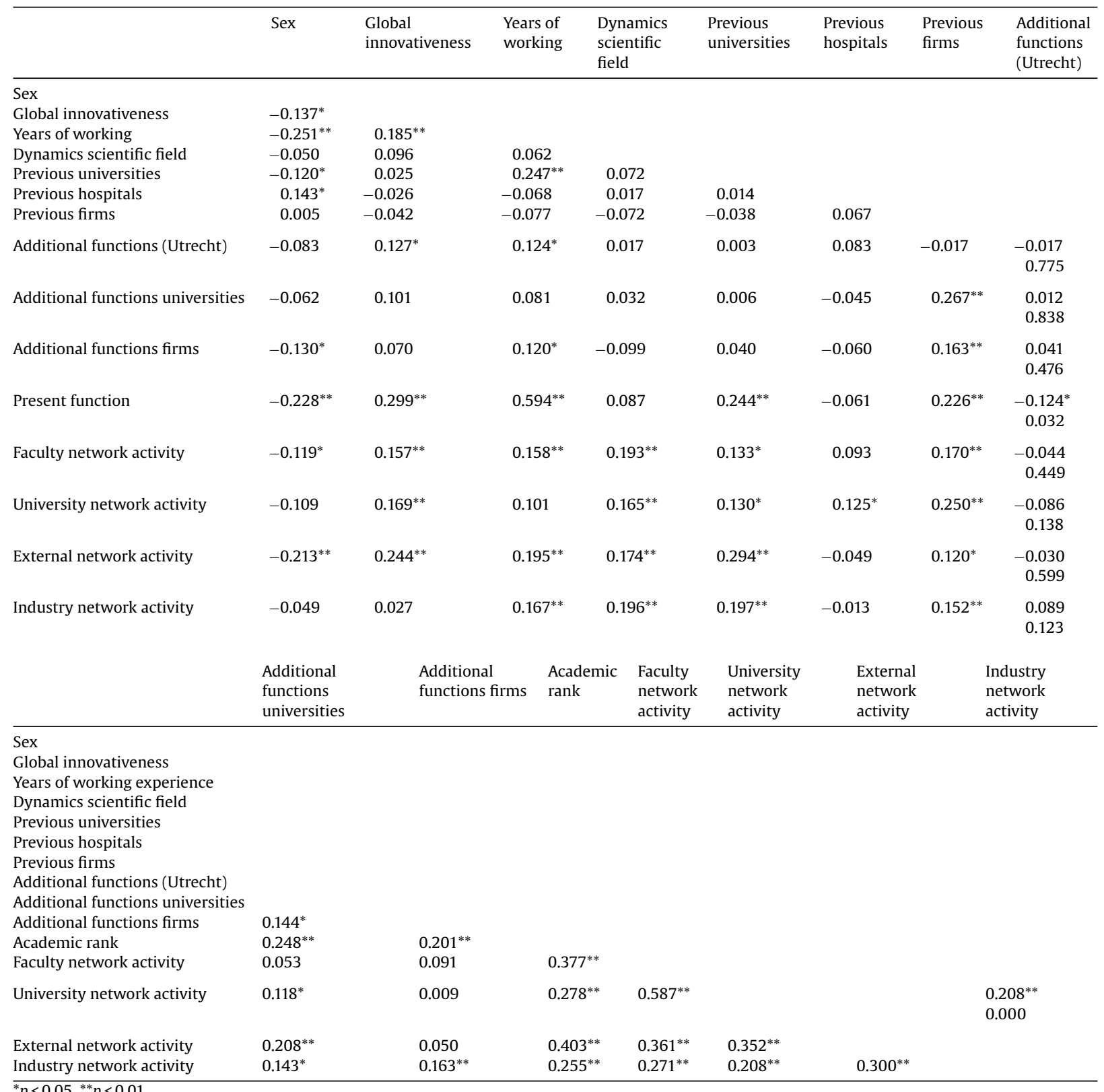

${ }^{*} p<0.05,{ }^{* *} p<0.01$. 


\section{References}

Albert, M., 2003. Universities and the market economy: the differential impact on knowledge production in sociology and economics. Higher Education (2), 147-182.

Ajzen, I., 2005. Attitudes. Personality and Behavior. Open University Press, Berkshire, England.

Aversi, R., Dosi, G., et al., 1999. Demand dynamics with socially evolving preferences. Industrial and Corporate Change 8 (2), 353-408.

Baruch, Y., Hall, D.T., 2004. The academic career: a model for future careers in other sectors? Journal of Vocational Behavior 64 (2), 241-262.

Bates, D., Sarkar, D., 2006. Ime4: Linear Mixed-effects Models Using S4 Classes. R Package Version 0.995-2.

Barney, J., 1991. Firm resources and sustained competitive advantage. Journal of Management 17 (1), 99-120.

Beaver, D.d., Rosen, R., 1978. Studies in scientific collaboration. Part I. The professional origins of scientific co-authorship. Scientometrics 1 (1), 65-84.

Bessant, J., Caffyn, S., et al., 2001. An evolutionary model of continuous improvement behaviour. Technovation 21 (2), 67-77.

Bourdieu, P., 1974. The specificity of the scientific field and the social conditions of the progress of reason. Social Science Information 6 (1), 10-35.

Bourdieu, 1983. Ökonomisches Kapital, kulturelles Kapital, soziales Kapital. In: Reinhard Kreckel (Ed.), Soziale Ungleichheiten (Soziale Welt, Sonderheft 2). Otto Schartz \& Co., Goettingen, pp. 183-198.

Bozeman, B., Corley, E., 2004. Scientists' collaboration strategies: implications for scientific and technical human capital. Research Policy 33 (4), 599-616

Carayol, N., 2003. Objectives, agreements and matching in science-industry collaborations: reassembling the pieces of the puzzle. Research Policy 32 (6), 887-908.

Chin, M.H., Covinsky, K.E., et al., 1998. Building a research career in general internal medicine-a perspective from young investigators. Journal of General Internal Medicine 13 (2), 117-122.

Cohen, W.M., Levinthal, D.A., 1990. Absorptive-capacity-a new perspective on learning and innovation. Administrative Science Quarterly 35 (1), 128-152.

Crane, D., 1970. Invisible Collages. Diffusion of Knowledge in Scientific Communities. The University Press of Chicago, Chicago.

Creed, P.A., Patton, W., et al., 2004. Internal and external barriers, cognitive style, and the career development variables of focus and indecision. Journal of Career Development 30 (4), 277-294.

Cyert, R.M., March, J.G., 1963. A Behavioral Theory of the Firm. PrenticeHall, Englewood Cliffs, NJ.

Devetag, M.G., 1999. From utilities to mental models: a critical survey on decision rules and, cognition in consumer choice. Industrial and Corporate Change 8 (2), 289-351.

Dietz, J.S., Bozeman, B., 2005. Academic careers, patents, and productivity: industry experience as scientific and technical human capital. Research Policy 34 (3), 349-367.

Etzkowitz, H., Leydesdorff, L., 1998. The endless transition: a "triple helix" of university-industry-government relations. Minerva 36, 203-208.

Etzkowitz, H., Leydesdorff, L., 2000. The dynamics of innovation: from National Systems and "Mode 2" to a Triple Helix of university-industry- government relations. Research Policy 29 (2), 109-123.

Feist, G.J., 1998. A meta-analysis of personality in scientific and artistic creativity. Personality and Social Psychology Review 4 (2), 290-309.

Fontana, R., Geuna, A., et al., 2006. Factors affecting university-industry R\&D projects: the importance of searching, screening and signalling. Research Policy 35 (2), 309-323.

Gibbons, M., Limoges, C., Nowotny, H., Schwartzman, S., Scott, P., Trow, M. 1994. The New Production of Knowledge: The Dynamics of Science and Research in Comtemporary Societies. SAGE, London.

Grant, R.M., 1996. Prospering in dynamically-competitive environments: organizational capability as knowledge integration. Organization Science 7 (4), 375-387.

Hagstrom, W., 1966. The Scientific Community. Basic Books, New York.

Harman, G., 1999. Australian science and technology academics and university-industry research links. Higher Education 38 (1), 83-103.

Harman, G., 2001. University-industry research partnerships in Australia: extent, benefits and risks. Higher Education Research \& Development 20 (3), 245-264.

Hannan, M.T., Freeman, J., 1989. Organizational Ecology. Harvard University Press, Cambridge, MA

Hessels, L.K., van Lente, H., 2008. Re-thinking new knowledge production: a literature review and a research agenda. Research Policy 28 (4), 740-760.
John, O.P., Srivastava, S., 1999. The big five trait taxonomy: history, measurement, and theoretical perspectives. In: Pervin, L.A., John, O.P. (Eds.), Handbook of Personality: Theory and Research. The Guilford Press, London, pp. 102-138.

Katz, J.S., Martin, B.R., 1997. What is research collaboration? Research Policy 26 (1), 1-18.

Kaufmann, A., Todtling, F., 2001. Science-industry interaction in the process of innovation: the importance of boundary-crossing between systems. Research Policy 30 (5), 791-804.

Kirton, M.J., 1976. Adaptors and innovators: a description and measure. Journal of Applied Psychology 61 (5), 622-629.

Kirton, M.J., 1994. A theory of cognitive style. In: Kirton, M.J. (Ed.), Adapters and Innovators: Styles of Creativity and Problem Solving. Routledge, London.

Kirton, M., 2003. Adaption-Innovation in the Context of Diversity and Change. Routledge, London.

Kogut, B., Zander, U., 1992. Knowledge of the firm, combinative capabilities, and the replication of technology. Organization Science 3 (3), 383-397.

Kuncel, N.R., Hezlett, S.A., et al., 2004. Academic performance, career potential, creativity, and job performance: can one construct predict them all? Journal of Personality and Social Psychology 86 (1), 148161.

Kwang, N.A., Rodrigues, D., 2002. A big-five personality profile of the adaptor and innovator. Journal of Creative Behavior 36 (4), 254-268.

LaFollette, M.C., 1992. Stealing into Print. Berkeley University of California Press.

Landry, M., Traore, N., Godin, B., 1996. An econometric analysis of the effect of collaboration on academic research productivity. Higher Education 32, 283-301

Latour, B., Woolgar, S., 1979. Laboratory Life. The Construction of Scientific Facts. Sage Publications, London.

Laudel, G., 2002. What do we measure by co-authorships? Research Evaluation 11 (1), 3-15.

Laursen, K., Salter, A., 2004. Searching high and low: what types of firms use universities as a source of innovation? Research Policy 33 (8), 1201-1215.

Lee, S., Bozeman, B., 2005. The impact of research collaboration on scientific productivity. Social Studies of Science 35 (5), 673-702.

Liberman, S., Wolf, K.B., 1998. Bonding number in scientific disciplines. Social Networks 20 (3), 239-246.

Luckhaupt, S.E., Chin, M.H., et al., 2005. Mentorship in academic general internal medicine-results of a survey of mentors. Journal of General Internal Medicine 20 (11), 1014-1018.

March, J.G., 1991. Exploration an exploitation in organisational learning. Organization Science 2 (1, Special Issue: Organisational Learning: Papers in Honor of (and by) James G. March), 71-87.

McCrae, R.R., John, O.P., 1992. An Introduction to the five-factor model and its applications. Journal of Personality 60, 175-215.

McCloy, R.A., Campbell, J.P., et al., 1994. A confirmatory test of a model of performance determinants. Journal of Applied Psychology 79 (4), 493-505.

McCullagh, P., 1980. Regression models for ordinal data. Journal of the Royal Statistical Society 42 (2), 109-142.

McCullagh, P., Nelder, J.A., 1998. Generalized Linear Models. Chapman \& Hall, London.

Meeus, M.T.H., Oerlemans, L.A.G., et al., 2004. Industry-public knowledge infrastructure interaction: intra- and inter-organizational explanations of interactive learning. Industry and Innovation 11 (4), 327352.

Melin, G., 2000. Pragmatism and self-organization-research collaboration on the individual level. Research Policy 29 (1), 31-40.

Melin, G., Persson, O., 1996. Studying research collaboration using coauthorships. Scientometrics 36 (3), 363-377.

Merton, R.K., 1968. The Matthew effect in science. Science 159 (3810), 56-63.

Meyer-Krahmer, F., Schmoch, U., 1998. Science-based technologies: university-industry interactions in four fields. Research Policy 27 (8), 835-851.

Mintzberg, H., 1989. The Professional Organization. Minzberg on Management. Free Press, New York.

Midgley, D.F., Dowling, G.R., 1978. Innovativeness: the concept and its measurement. Journal of Consumer Research 4 (4), 229242

Nelson, R.R., Winter, S.G., 1982. An Evolutionary Theory of Economic Change. The Belknap of Harvard University Press, Cambridge, MA

Nieminen, M., Kaukonen, E., 2001. In: Kaitila, S. (Ed.), Universities and R\&D Networking in a Knowledge-based Economy. Sitra Reports Sitra, Helsinki. 
Oerlemans, L.A.G., Meeus, M.T.H., et al., 1998. Do networks matter for innovation? The usefulness of the economic network approach in analysing innovation. Tijdschrift Voor Economische En Sociale Geografie 89 (3), 298-309.

Oh, W., Choi, J.N., et al., 2005. Coauthorship dynamics and knowledge capital: the patterns of cross-disciplinary collaboration in information systems research. Journal of Management Information Systems 22 (3), 265-292.

Penrose, E.T., 1959. The Theory of the Growth of the Firm. M.E. Sharpe, White Plains, NY.

R Development Core Team, 2006. R: A Language and Environment for Statistical Computing. R Foundation for Statistical Computing, Vienna, Austria. ISBN 3-900051-07-0, URL http://www.R-project.org.

Richerson, P.J., Boyd, R., 2005. Not by Genes Alone: How Culture Transformed Human Evolution. The University of Chicago Press, Chicago/London.

Slaughter, S., Leslie, L.L., 1997. Academic Capitalism: Politics, Policies, and the Entrepreneurial University. The John Hopkins University Press, Baltimore.
Shinn, T., 2002. The Triple Helix and new production of knowledge: prepackaged thinking on science and technology. Social Studies of Science 32 (4), 599-614.

Smits, R., Den Hertog, P., 2007. TA and the management of innovation in economy and society. International Journal of Foresight and Innovation Policy 3 (1), 28-52.

Tuunainen, J., 2005. Hybrid practices? Contributions to the debate on the mutation of science and university. Higher Education 50 (2), 275-298.

Van Rijnsoever, F.J., Castaldi, C., 2008. Knowledge base, information search and intention to adopt innovation, WP \#08.02. ISU Working Paper Series, Utrecht University.

Weingart, P., 1997. From "finalization" to "Mode 2": old wine in new bottles? Social Science Information Sur Les Sciences Sociales 36 (December (4)), 591-613.

Wenger, E., 1998. Communities of Practice: Learning, Meaning, and Identity. Cambridge University Press, Cambridge.

Ziman, J., 2000. Real Science: What it is, and What it Means. Cambridge University Press, Cambridge. 